Table. Charactheristics of studies included in the meta-analysis and of the studied patients

\begin{tabular}{|c|c|c|c|c|c|c|c|}
\hline Author and year & Design & Country & $\mathrm{N}^{\circ}$ of patients & Age (years) & Male sex & HLAB27+ & Disease duration (years) \\
\hline Al-Osami 2018 & cohort & Iran & 170 & $36.1(9.0)$ & $158(93)$ & $68(40)$ & $8.3(5.9)$ \\
\hline Durcan 2012 & cross-sectional & Ireland & 46 & $45.1(11.2)$ & $35(76)$ & $N / D$ & $12.9(10.9)$ \\
\hline Hernandez-Breijo 2019 & cohort & Spain/Netherlands & 180 & $47.0(12.7)$ & $107(59)$ & $131(73)$ & $8.0(5.9)$ \\
\hline Lee 2017 & cross-sectional & China & 194 & 38.7 (13.7) & $150(77)$ & 159 (82) & $7.1(8.6)$ \\
\hline Maas 2016 & cross-sectional & Netherlands & 461 & $45.3(12.8)$ & $303(66)$ & $361(80)$ & $17(15.2)$ \\
\hline Micheroli 2017 & cohort & Switzerland & 624 & $39.4(11.6)$ & $388(62)$ & $487(78)$ & $13(10.9)$ \\
\hline O'Shea 2015 & cross-sectional & Ireland & 267 & $47.8(\mathrm{~N} / \mathrm{D})$ & $212(79)$ & $N / D$ & $21.7(\mathrm{~N} / \mathrm{D})$ \\
\hline Ottaviani 2012 & cohort & France & 155 & $43.1(12.4)$ & $98(63)$ & $96(65)$ & $8.0(4.8)$ \\
\hline Rosas 2017 & cross-sectional & Spain/Mexico & 57 & $47.1(10.4)$ & $37(65)$ & $44(77)$ & $9.8(9.3)$ \\
\hline Rubio-Vargas 2016 & cross-sectional & Netherlands & 168 & $30.2(8.2)$ & $81(48.2)$ & $156(93)$ & $N / D$ \\
\hline
\end{tabular}

Legend. Results are expressed as mean (SD) or number of patients (\%). HLA= Human Leukocyte Antigen; N/D= not determined

Conclusion: Poor health status is associated with disease activity, poor quality of life and functional activity. ASAS $\mathrm{HI}$ has a good correlation with other parameters to evaluate $\mathrm{SpA}$, reinforcing the construct validity of this new tool.

References:

[1] Kiltz U, et al. Ann Rheum Dis 2018;0:1-7.

Disclosure of Interests: None declared

DOI: 10.1136/annrheumdis-2020-eular.5029

\section{FRI0319 DO OBESITY AND OVERWEIGHT INFLUENCE DISEASE ACTIVITY MEASURES IN AXIAL SPONDYLOARTHRITIS? A SYSTEMATIC REVIEW AND META-ANALYSIS}

A. Ortolan ${ }^{1}$, M. Lorenzin ${ }^{1}$, M. Felicetti ${ }^{1}$, R. Ramonda ${ }^{1} .{ }^{1}$ University of Padova, Rheumatology Unit, Department of Medicine DIMED, Padova, Italy

Background: obesity is apparently related with worse treatment response in axial spondyloarthritis (axSpA). However, it is unclear whether obesity or overweight per se are associated to higher disease activity scores compared to nonobese individuals, and what is the effect size of this difference.

Objectives: to investigate whether overweight/obesity are associated to higher disease activity as measured by Bath Ankylosing Spondylitis Disease Activity Index (BASDAl) or Ankylosing spondylitis disease activity score (ASDAS) in axSpA patients.

Methods: MEDLINE, PubMed and Web of Science were searched using key terms corresponding to population (axSpA), exposure (overweight/obesity) and outcome (BASDAI, ASDAS). Predefined inclusion criteria were: 1) adult axSpA patients, both radiographic and non-radiographic 2) exposure classified according to Body Mass Index-BMI-; 3) BASDAI/ASDAS reported for each BMI group; 4) observational studies. Patients classified according to CASPAR or Moll\&Wright criteria for psoriatic arthritis were excluded. Newcastle-Ottawa Scale for cohort, cross-sectional and case-control studies was used for quality check. BASDAI and ASDAS estimates were reported as mean difference (MD) and standard deviation (SD) between the normal BMI axSpA patients and the overweight or obese patients. The statistical heterogeneity of meta-analysis was assessed using the $\mathrm{I}^{2}$ statistic. Random-effects meta-analysis was used to pool results.

Results: A total of 330 references were generated by the database search. After removing duplicates, 250 references remained and were assessed for eligibility. A further 206 articles were excluded by titles and abstracts' reading, 44 articles were examined full text. Only 11 articles fulfilled inclusion/exclusion criteria. Following quality check, 10 articles were finally included in the meta-analysis (Table). Among these, 4 studies reported two BMI groups (normal vs overwight+obese), while 6 studies reported three (normal, overweight, obese). In the studies reporting 3 BMI group, weighted means and standard deviation were calculated to create a merged overweight+obese group. The mean difference (MD) between pooled BASDAI and ASDAS of normal BMI patients and those of overweight+obese patients were respectively -0.38 (95\% Cl: $-0.56,-0.21)$ and $-0.19(95 \% \mathrm{Cl}:-0.29,-0.09)$. In the articles reporting $3 \mathrm{BMI}$ groups, the MD between BASDAI of normal BMI and overweight only patients was -0.09 ( $95 \% \mathrm{Cl}:-0.33 ; 0.15)$; between normal $\mathrm{BMI}$ and obese only patients MD was $-0.77(95 \% \mathrm{Cl}-1.07 ;-0.48, \mathrm{p}<0.0001)$ (Figure). Heterogeneity statistics revealed low estimates, though with wide $\mathrm{Cl}$ across all the groups (Figure).

Conclusion: disease activity scores of normal BMI axSpA patients tend to be lower than overweight or obese patients. However, this difference seems to be relevant in practice especially when normal BMI patients are compared to truly obese patients $(\mathrm{BMI} \geq 30)$.
Figure. Results of the meta-analysis of Bath Ankylosing Spondylitis Disease Activity Index (BASDAI) in normal BMI vs overweight or obese individuals $(A)$; in nom al BMI vs overweight individuals $(C)$; in normal $B M I$ vs obes or obese indisiduals $(B)$
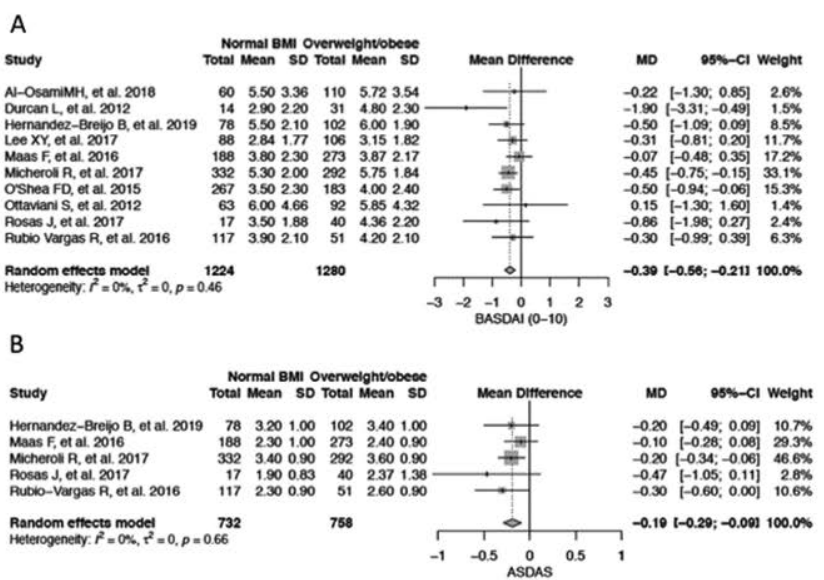

C

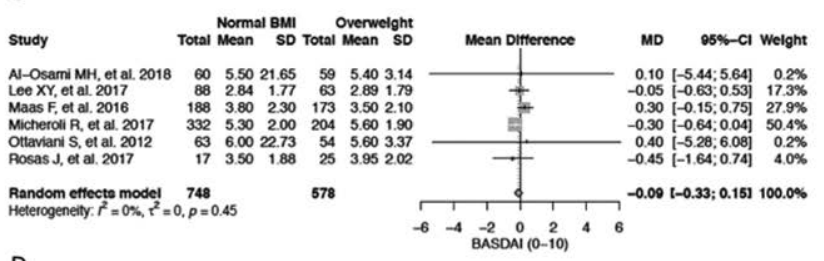

D

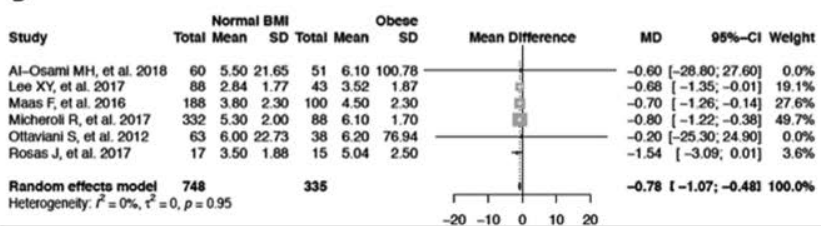

Disclosure of Interests: Augusta Ortolan: None declared, Mariagrazia Lorenzin: None declared, Mara Felicetti: None declared, Roberta Ramonda Speakers bureau: Novartis, Celgene, Janssen, Pfizer, Abbvie, Lilly DOI: 10.1136/annrheumdis-2020-eular.3183

\begin{tabular}{|l|l|}
\hline FRI0320 & MULTICENTER VALIDATION OF THE DETECTION OF \\
ARTHRITIS IN INFLAMMATORY BOWEL DISEASES \\
(DETAIL) QUESTIONNAIRE FOR THE SCREENING \\
OF SPONDYLOARTHRITIS IN PATIENTS WITH \\
INFLAMMATORY BOWEL DISEASES
\end{tabular}

L. Perini ${ }^{1}$, D. Benfaremo ${ }^{1}$, V. Marconi ${ }^{1}$, V. Paci ${ }^{1}$, M. DI Carlo ${ }^{1}$, F. Salaffi ${ }^{1}$, M. M. Luchetti ${ }^{1}$, A. Gabrielli ${ }^{1}$ on behalf of GRADES-IBD Study Group. ${ }^{1}$ Università Politecnica delle Marche, Dipartimento di Scienze Cliniche e Molecolari, Ancona, Italy

Background: Spondyloarthritis (SpA) is the most frequent extra-intestinal manifestation in inflammatory bowel diseases (IBD), since it may occur in up to $25 \%$ of patients. The early referral to a Rheumatology Unit may lead to proper treatment and better outcomes for patients with suspect SpA. Recently, we have developed 
and preliminarily validated a self-administered screening questionnaire, called DETection of Arthritis in Inflammatory boweL diseases (DETAIL) ${ }^{1}$

Objectives: To validate the DETAIL questionnaire in a multicenter cohort of IBD patients enrolled at ten Gastroenterology and Rheumatology Units in Italy. Methods: The DETAIL instrument is a 6-item questionnaire developed through a Delphi method ${ }^{1}$. From October 2018 to March 2019, consecutive adult patients with IBD, Crohn's disease (CD) or ulcerative colitis (UC), filled out independently the DETAIL in the outpatient waiting room. Thereafter, within 2 weeks a blinded rheumatologist assessed all the patients, irrespectively of the DETAIL results, and classified them to be affected or not by SpA according to ASAS criteria. The performance of the DETAIL was evaluated trough Bayesian analysis, defining for each item of the questionnaire the sensitivity, specificity, positive (LR+) and negative (LR-) likelihood ratios.

Results: Overall, 418 IBD patients filled out the DETAIL questionnaire. Upon rheumatological evaluation, 102 (24.4\%) patients received a diagnosis of SpA. Of the six questions, the best performances were found in item $6(L R+3.77)$, reporting inflammatory back pain at night, and in item $3(L R+3.31)$, exploring Achilles enthesitis. The presence of back pain lasting more than three months $(L R+2.91)$, of back pain with inflammatory features $(L R+2.55)$ and a history of dactylitis $(L R+2.55)$, showed also a fairly good performance, whereas a history of peripheral synovitis was slightly worse $(L R+2.16)$. The combination of at least three items answered affirmatively yielded a post-test probability of SpA of $75 \%$ or more. The presence of alternative diagnoses, such as osteoarthritis and fibromyalgia, represented a minor confounder.

Conclusion: The DETAIL questionnaire is the first screening tool for the early detection of SpA/IBD that has been validated by a multicenter study group. References:

[1] Di Carlo M, Luchetti MM, Benfaremo D, Di Donato E, Mosca P, Maltoni S, Benedetti A, Gabrielli A, Grassi W, Salaffi F. The DETection of Arthritis in Inflammatory boweL diseases (DETAIL) questionnaire: development and preliminary testing of a new tool to screen patients with inflammatory bowel disease for the presence of spondyloarthritis. Clin Rheumatol. 2018 Apr;37(4):1037-1044

Acknowledgments: We are grateful to all the members of the GRADES-IBD study group for their outstanding help in the enrollment of patients.

We also would like to acknowledge the "Società Italiana di Gastro-Reumatologia" (SIGR) for its help and assistance in the constitution of the multidisciplinary network.

Disclosure of Interests: None declared

DOI: 10.1136/annrheumdis-2020-eular.3726

\section{\begin{tabular}{|l|l}
\hline FRI0321 UTILITY OF THE ASAS HEALTH INDEX \\
\hline
\end{tabular} QUESTIONNAIRE AS A TOOL FOR HEALTH ASSESSMENT IN PATIENTS WITH SPONDYLOARTHRITIS AND ITS ASSOCIATION WITH DISEASE ACTIVITY, FUNCTIONALITY, MOBILITY, AND STRUCTURAL DAMAGE}

M. Á. Puche Larrubia ${ }^{1}$, C. López-Medina ${ }^{1,2}$, M. D. C. Castro Villegas ${ }^{1}$, R. Ortega Castro $^{1}$, M. Ladehesa Pineda ${ }^{1}$, P. S. Laura ${ }^{1}$, G. G. Ignacio ${ }^{1}$, J. M. SequíSabater $^{1}$, M. D. C. Abalos-Aguilera ${ }^{1}$, I. C. Aranda-Valera ${ }^{1}$, G. C. Juan Luis ${ }^{1}$, A. Escudero Contreras ${ }^{1}$, E. Collantes-Estevez ${ }^{1} .{ }^{1}$ Reina Sofia University Hospital, Rheumatology Service/IMIBIC/Cordoba University, Córdoba, Spain; ${ }^{2}$ Cochin Hospital, Rheumatology Service, Paris, France

Background: The ASAS Health Index (ASAS-HI) questionnaire, a tool that measures the impact of the disease on the health in patients with Spondyloarthritis $(\mathrm{SpA})$, has been recently validated. However, there are still no studies evaluating the utility of this questionnaire in daily clinical practice.

Objectives: The objective of this study is to evaluate the association of ASAS-HI with disease activity, functionality, mobility, and structural damage in patients with SpA.

Methods: This is an observational, cross-sectional and single-center study in which 126 consecutive patients with SpA were included. Sociodemographic data, scores related to disease activity (BASDAI and ASDAS), functionality (BASFI), structural damage (cervical, lumbar and total mSASSS), mobility (BASMI and UCOASMI), quality of life (ASAS-HI) and the presence of concomitant fibromyalgia (evaluated with the FIRST questionnaire) were obtained from all patients. The ASAS-HI questionnaire was considered as the main outcome (scale from 0 to 17). Pearson's correlation coefficient was used to evaluate the association of the different continuous variables with each other. Student's t-test was used to compare the ASAS-HI between different subgroups of patients (men vs. women, ASDAS $>2,1$ vs. ASDAS $\leq 2,1$ and fibromyalgia + vs. fibromyalgia-). Finally, a multivariate linear regression was performed to determine which factors explain the variability of ASAS-HI in these patients Results: Among the 126 patients included, 83 (65.9\%) were men, with a mean age of $45.1 \pm 12.3$ years and a mean disease duration of $18.7 \pm 14.5$ years. The mean ASAS-HI score in all patients was $4.7 \pm 4.0$, showing a "strong" positive linear correlation $(r>0.60)$ with BASDAI and BASFI, and "moderate" positive
( $r=0.40$ to 0.60 ) with Global VAS and ASDAS (Figure 1). Patients with fibromyalgia showed a significantly higher ASAS-HI score compared with patients without fibromyalgia ( $9.5 \pm 3.2$ vs $3.7 \pm 3.4$, respectively). In addition, patients with high disease activity (ASDAS $>2,1$ ) showed a higher mean score in ASAS-HI compared with those with low activity (ASDAS $\leq 2,1)(5.8 \pm 3.8$ vs $2.0 \pm 2.4$ $\mathrm{p}<0,001)$.

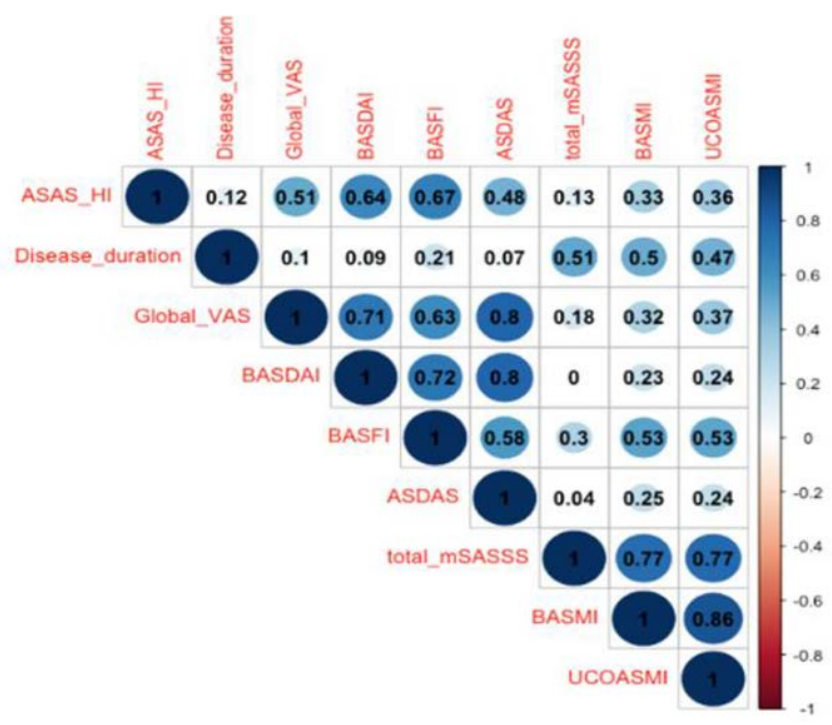

Figure 1. Simple linear correlation (Pearson's $r$ ) between the different variables studied.

Finally, multiple linear regression showed that $57,4 \%(R 2=0,574)$ of the ASAS-H variability is explained by the presence of concomitant fibromyalgia $(\beta=2.23$, $95 \%$ IC 0.73 to $3.80, p=0.004$ ), BASDAI ( $\beta=0.62,95 \%$ IC 0.25 to $0.97, p=0.001$ ) and BASFI ( $\beta=0.57,95 \%$ IC 0.26 to $0.88, p=0.001)$.

Conclusion: In our study, the impairment of the quality of life in patients with SpA was mainly associated with a high disease activity (BASDAI), worsening functionality (BASFI) and with the presence of concomitant fibromyalgia. Neither mSASSS nor UCOASMI was associated with a change in ASAS-HI; thus, in our patients neither structural damage nor mobility seem to influence the quality of life. In a patient with a high ASAS-HI we must evaluate the presence of concomitant fibromyalgia.

Acknowledgments: The authors wish to thank all patients who participated in the study.

Disclosure of Interests: María Ángeles Puche Larrubia: None declared, Clementina López-Medina: None declared, María del Carmen Castro Villegas: None declared, Rafaela Ortega Castro: None declared, MLourdes Ladehesa Pineda: None declared, Pérez Sánchez Laura: None declared, Gómez García Ignacio: None declared, José Miguel Sequí-Sabater: None declared, Maria del Carmen Abalos-Aguilera: None declared, Inmaculada Concepcion Aranda-Valera: None declared, Garrido Castro Juan Luis: None declared, Alejandro Escudero Contreras Grant/research support from: ROCHE and Pfizer, Speakers bureau: ROCHE, Lilly, Bristol and Celgene., Eduardo Collantes-Estevez: None declared DOI: 10.1136/annrheumdis-2020-eular.5640

\section{FRI0322 INSULIN RESISTANCE IN NON-DIABETES PATIENTS WITH SPONDYLOARTHRITIS}

J. C. Quevedo-Abeledo ${ }^{1}$, F. Genre ${ }^{2}$, J. Rueda-Gotor ${ }^{3}$, A. Corrales ${ }^{3}$,

V. Hernández-Hernández ${ }^{4}$, N. Fañanas-Rodríguez ${ }^{5}$, B. Lavín-Gómez ${ }^{5}$, D. F. Esmeralda ${ }^{4}$, A. De Vera-González ${ }^{6}$, A. Delgado-González ${ }^{6}$, L. De ArmasRillo $^{7}$, M. T. García-Unzueta ${ }^{5}$, M. A. González-Gay ${ }^{3}$, I. Ferraz-Amaro ${ }^{4}{ }^{1}$ Division of Rheumatology, Hospital Doctor Negrín, Las Palmas de Gran Canaria, Spain, Las Palmas de Gran Canaria, Spain; ${ }^{2}$ Epidemiology, Genetics and Atherosclerosis Research Group on Systemic Inflammatory Diseases, Hospital Universitario Marqués de Valdecilla, IDIVAL, Santander, Spain; ${ }^{3}$ Division of Rheumatology, Hospital Universitario Marqués de Valdecilla, Santander, Spain; ${ }^{4}$ Hospital Universitario de Canarias, Division of Rheumatology, Santa Cruz de Tenerife, Spain; ${ }^{5}$ Division of Endocrinology, Hospital Universitario Marqués de Valdecilla, Santander, Spain; ${ }^{6}$ Division of Central Laboratory, Hospital Universitario de Canarias, Tenerife, Spain, Santa Cruz de Tenerife, Spain; ${ }^{7}$ Universidad Europea de Canarias, Santa Cruz de Tenerife, Spain

Background: Insulin resistance (IR) is a state in which a given concentration of insulin is associated with a subnormal glucose response. IR constitutes a major underlying abnormality driving cardiovascular disease in the general population 